\title{
Mineshaft Roller Bearing Failure Analysis
}

\author{
Ronald J. Parrington,* and David M. Christie* \\ * IMR Test Labs, 131 Woodsedge Drive, Lansing, NY 14882
}

The inner rotating ring of a 1.2 meter diameter spherical roller bearing used in a 27 metric ton mining hoist application fractured after just one year of service. The failure mechanism involved subsurface origin rolling contact fatigue or pitting of the motor-side inner raceway followed by low cycle fatigue fracture of the inner ring. Features of this failure which are atypical of roller element bearing failures are the short life span of the bearing, the fracture of the inner ring, and the presence of intergranular fracture features.

The subsurface origin pitting damage was limited to a region $30 \mathrm{~cm}$ in length and was roughly centered in the width of the race. Subsurface origin rolling contact fatigue cracks initiated at unusual depths (up to $1 \mathrm{~mm}$ from the raceway surface) and were accompanied by microstructural alterations (i.e., untempered martensite or stress butterflies) as shown in Fig. 1. Subsurface origin pitting normally occurs at a depth of just a fraction of a millimeter. In this case, the subsurface origin pitting is deeper than usual due to the large scale of the bearing components [1].

Typical of subsurface origin rolling contact fatigue, branch cracks formed between the subsurface cracks and the surface of the raceway. However, one of the branch cracks running parallel with the raceway turned away from the race surface and towards the inner ring ID. It then propagated by a series of small overload crack extensions (i.e., low cycle fatigue) to a maximum depth of $3.4 \mathrm{~cm}$ and culminated in overload fracture of the inner ring. The fracture surface is shown in Fig 2.

Interestingly, thin bands of intergranular fracture were associated with the low cycle fatigue region and were visible as beach marks on the fracture surface. The intergranular fracture morphology was reproduced in the laboratory by notching two opposing sides of a small piece of the inner ring, and then squeezing one notch shut in a vice, placing the other notch in tension. A small region of intergranular fracture was noted near the fracture "hinge" close to the compressed notch. The balance of the fracture was ductile. In contrast, laboratory fracture of three pieces of stock AISI E 52100 bearing steel (very similar composition to the subject bearing) hardened to $59 \mathrm{HRC}$ failed to result in intergranular fracture. Although the material chemistry, microstructure, and hardness are consistent with good bearing manufacturing practices, these observations suggest that heat treatment embrittlement may have contributed to the mineshaft bearing failure.

The limited region of subsurface cracking and the step-wise extension of the major crack suggest that the bearing is experiencing overload conditions, possibly as load spikes or vibration at some point during shaft rotation. The most likely position for the bearing damage would be on the downward facing side of the shaft at starts and stops. The through-wall fracture of the inner ring is not typical of bearing failure, and may indicate excessive hoop stress.

References

[1] R.C. Juvinall and K.M. Marshek, Fundamentals of Machine Component Design, $2^{\text {nd }}$ ed., John Wiley, 1991. 


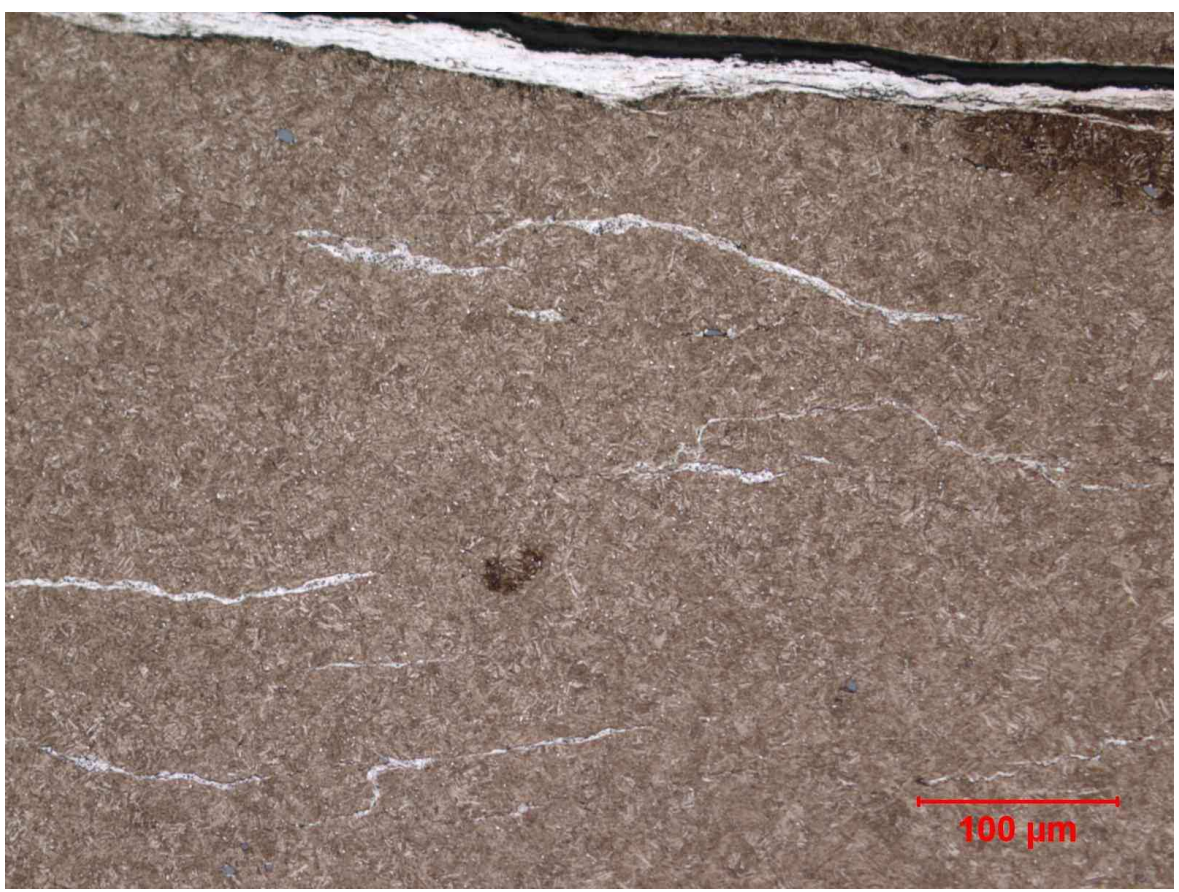

FIG. 1. Microstructural alterations (i.e., untempered martensite or stress butterflies), indicative of high Hertzian stresses, are associated with the region of subsurface origin rolling contact fatigue.

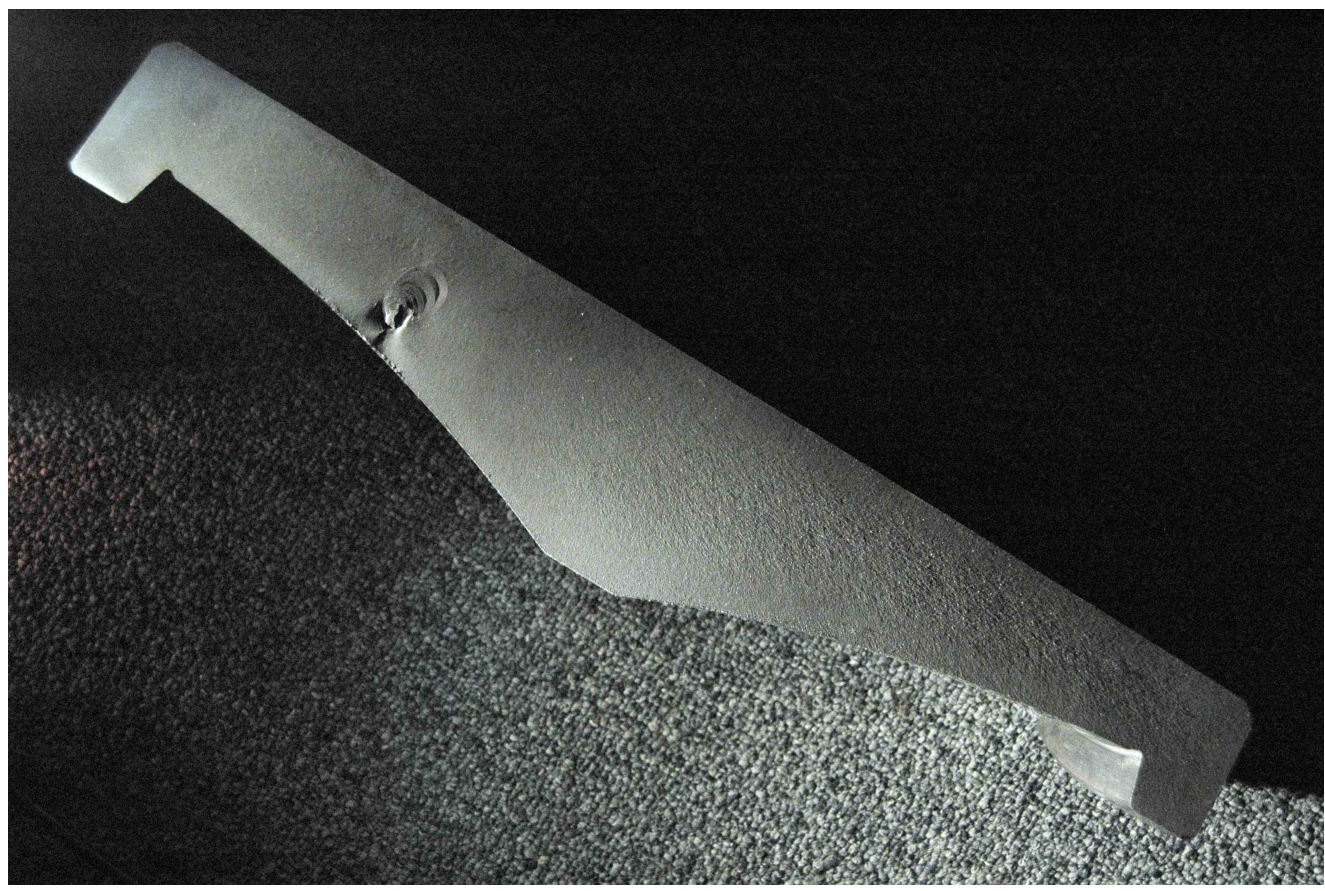

FIG. 2. Fracture surface of the bearing inner ring 